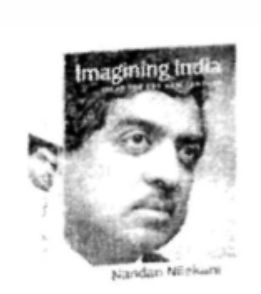

\title{
Let's imagine future of India: with the ideas that ignite
}

"Imagining India" - ideas for the new century,

Mr. Nandan Nilekani, Co- Chairman, Infosys Itd., Penguin books, 2008, pp 531, Price: 699

ASHWINI N. RAICHUR *

India - young, confident, awake, vibrant and powerhouse of opportunities, resources, hopes, aspirations - we have had a long journey of evolution and transformation to be where we are. All strengths of the country have come together in right combination and matured together which give it a unique advantage over many other countries to tap the global opportunities and that makes India so significant. India, its growth and challenges have been a topic of exploration and research, issue of concern and debate for many eminent people- sociologists, economists, politicians, businessmen, visionaries- around the world. Efforts invested in understanding, analyzing and predicting these trends, are justified as the phenomenon being so very complex, humungous and constantly changing.

Nandan Nilekani - personification of India's IT revolution as the co-founder of Infosys, has brought about a very distinctive and unique perspective to gamut of issues concerning future of our nation. He was chosen by Time magazine as one of the hundred most influential people in the world. The book is a compilation of 18 ideas of an entrepreneur, socialist, reformer, philosopher, businessman and above all a true Indian, who has woven rich and a realistic fabric of optimism by integrating them.

The book is divided into four main parts which classify ldeas that have arrived, Ideas in progress, Ideas in Battle and Ideas to anticipate. Across the narration he brings a perspective that it is just not the economic growth that spurs development of the nation unless the reforms are brought about in all spheres of the society.

\section{History revisited}

Different parts of the book cover various moments in history of different countries and that of India with a clear analytical and explanatory approach which is the bedrocks of the present. Be it transformation of England during Industrial revolution or be it post independence north south squabble over national language, every thought comes logically connected providing a meaningful insight and explanation to what we are experiencing today.

The first part presents the current scenario of changing attitude of India towards population, entrepreneurs, English language, globalization and democracy. Author quotes that the ultimate resource to any economic activity is the Human imagination and also goes into the history of family planning policy of India to talk how once perceived as millions on an ant hill could be turned to advantage to earn demographic dividend. Demographic trends across the world with a comparative note to India's demographic evolution are also presented describing people advantage in democratic and autocratic environments.

"HOD, Post-Graduate Department of Management Studies, SRN Adarsh College, Bangalore

Mobile : 99800 12686, E-mail : raichurashwini@yahoo.co.in 
Entrepreneurial capital is something which the author quotes as an essential ingredient for taking on India forward. Attitude transformation towards entrepreneurship - from criticism to suspicion to appreciation has been captured well with self experiences during 1980s. What makes a very interesting read in this part is analysis of indian history which has lead to blend of English, explicitly with Indian Identity. Technology is viewed as enabler and as a means for upward mobility and tool for people to make their lives easier. With a soft take on globalization author provides an insight to the process that has provided both good and bad global integration. Finally the section closes with a clear explanation on adoption of democracy as fundamental political system post independence and how Democracy in India has shifted from being essentially foreign to simply essential

\section{Reality check - the sweet spot}

The second and third section of the book is a real eye opener to the challenges that India is encountering today - be it education system or the governance and leadership issue. The author emphasizes on the point that it is inevitable to Unshackle higher education institutions from the hold of state and the interest groups where in they can become important shapers of political opinions. Concept of universal education, decentralization and other reforms in education system are loudly thought as the ideas that can be enablers for India's march forward. The issues associated with urbanization, infrastructure, and employment are realistically presented in a view that the book provides a direction towards optimism, solutions and hope. The author talks about how the cities are expanding haphazardly; infrastructure is way below the satisfactory level and there are too many walls in the way of a single market. Third section happens to be the most powerful section where he discusses as to how we as a country have failed miserably in sectors that have impeded our growth.

\section{Transcending Ideas}

The final section of the book touches upon the challenges that India will have to encounter in coming decades in terms of health, energy, environment and social security issues. He contends that as a country we need to learn from the mistakes of other developed countries and develop innovative ideas to avoid damaging consequences

Though the book covers number of issues with a wide scope, the approach of how ideas act as the change agents makes it unique and interesting. The thoughts of hundreds of minds have provided inputs and analysis providing it the required depth and width. At times issues are repeated as a result of its complexity. But as Friedman rightly quotes him to be a great explainer, explanation is a must read to synthesize from thereon and imagine future of India. 
AJMR

Adarsh Journal of Management Research (AJMR) is biannual journal published every September and March. Its mission is to integrate and propagate the rich perspectives of management repository. The journal endeavours to promote research in different functional areas of management and on issued related to economy, industry and environmen1.

\section{Disclaimer}

The views expressed by the author(s) are their own and does not necessarily reflect the organisation that they belong to or that of SRN Adarsh College. All articles in this journal, unless otherwise noted, have undergone a blind review process

\section{Submissions}

We encourage prospective authors to follow the guidelines provided at the end of this journal before submitting manuscripts.

Please direct all your manuscripts to - Editor-in-Chief, Adarsh Journal of Management Research, Department of Management Studies, SRN Adarsh College, \# 75, 5th Main,Chamarajpet, Bangalore 560018.

\section{Copyright}

The contents of this journal are the copyright of Adarsh Vidya Sangh, Bangalore, whose permission is necessary for reproduction in any form or in part. 